\title{
Gynae-cytological Evaluation of Cervical Cancer Among Women (Age d15-60 Years) Attended University of Nigeria Teaching Hospital, Ituku Ozalla, Enugu Between 2009-2014
}

\author{
Henry E. Aloh¹, OMORDION NT2², Eze Richard Ikechukwu³, Achukwu PU4, Agbo Julius Amechi4 \\ ${ }^{1}$ Health Economics and Research Unit, Department of Health Services, Alex Ekwueme Federal University, Ndufu-Alike Ikwo, Ebonyi \\ State, Nigeria \\ ${ }^{2}$ Health Services Department, University of Benin, Benin City, Benin City, Nigeria \\ ${ }^{3}$ Department of Anatomy, College of Medicine, Federal University, Lafiya, Nasarawa State \\ 4Department of Medical Laboratory Science, Faculty of Health Science and Technology, University of Nigeria, Enugu Campus, Enugu
}

\section{*Corresponding Author}

OMORDION Nosa Terry

\section{Article History}

Received: 24.09.2019

Accepted: 07.10 .2019

Published: 05.11.2019

\begin{abstract}
This work was designed to access the incidence of cervical cancer in UNTH using already diagnosed cervical samples collected from the Morbid Anatomy cancer unit of UNTH Ituku-Ozalla Enugu. Forty (40) cervical carcinoma samples were collected from the study and four (4) earlier diagnosed negative samples were used as "control". The sections were stained using Haematoxylin and eosin method. Out of the 40 cervical carcinoma samples obtained, the result showed that the age group 40-44 years has the highest frequency of positive cases. Also the result showed that the number of positive cases increased with parity some samples observed showed normal squamous epithelia and absence of tumor cells hence negative for cervical cancer; while some slides showed the features of carcinoma and precancerous growth hence positive. Apart from habit and acts leading to high positive cases, most cases have un explained causes.
\end{abstract}

Keywords: Exfolliative cytopathology, Leisions, desquated.

\section{INTRODUCTION}

Exfoliative cytopathology is the study of normal and the disease altered desquamated cell [1]. It entails the microscopical examination and interpretation of cells which are shaded (exfoliated) desquamated spontaneously from epithelial surfaces of the body, or which may be removed from such surface or membranes by physical means. Because of the need for continuous renewal of the body tissue, cellular exfoliation is an unceasing process [1]. The rate of desquamation varies with each tissue, its function, and metabolic activities. Some of these desquamated cells accumulate in natural cavities and is recesses. There are two types of cellular exfoliation from which samples are studied [1].

Physiological desquamated cells will often show, besides the pathologic changes and the normal changes of natural ageing, the results of their separation from conferment in the organized structures. The samples cells to be studied are usually suspended in the fluid and removed by bulb of syringe aspiration. Good sample are the accumulation of cervice vaginal pool secretion, in the posterior formix and of mesothelial cells in the effusion of the pleural and abdominal cavities [1].

Artificial exfoliation occurs when the surface of mucosa is scrapped and viable cells are traumatically exfoliated before their nature time of shedding. According to the type of information desired, the scrapping will be firm as in the case of cervical carcinoma where the deep basal cells are needed for examination, or very gentle, as in the case of hormonal studies where the cells desired must come from the surface layer of the vaginal mucosa. The artificial exfoliated cells often appear in sheet and are smaller and less mature than the spontaneously desquamated ones $[2,3]$.

Copyright @ 2019: This is an open-access article distributed under the terms of the Creative Commons Attribution license which permits unrestricted use, distribution, and reproduction in any medium for non commercial use (NonCommercial, or CC-BY-NC) provided the original author and source are credited. 
It is worthy of mention here that cytopathology has certain advantages over histopathology. Cytopathologic method provides a rapid and simple means of diagnosis that can on occasions supplement or replace a frozen section or a biopsy. The cytopathologic process no injury to tissues and allows frequent repetition of cellular sampling important in the elevation if the progression or posttreatment regression of a lesion. The smears cover a wider surface than that involved in biopsy. The cells can be obtained from areas inaccessible to a biopsy, for example, from the bottom of a crypt [1-3]. The intimate cellular structures are often more clearly seen isolated cell of a smear because of the minimum shrinkage and distortion in such cells. Furthermore the entire cell is studied in three dimensional views, not merely a section from it.

The vaginal smears permit an easier evaluation of the hormonal status of a patient and the type of genital inflammation. However, cytopathologic cellular changes are based mainly on individual observation and often cannot be forced into grid criteria. The cytopathological diagnosis is not final; it must be confirmed via histology [1-3].The screening of a smear can be time consuming. Often, the nature of the lesion is not as obvious as in the histologic section. The interrelation and arrangement of the cells cannot be established. Neighboring cells in a smear often originate from different part of an organ. The relation of the cells to the supporting stroma cannot be determined by cytology, which is important in the diagnosis of an invasive carcinoma. The size of the lesion cannot be approximate by cytology, since the number of exfoliated cells often has no relation to the size of lesion. The type of lesion, in-situ, as compared with early invasion, adenocarcinoma, or sarcoma, is more difficult to determine by a smear [1-3]. The sample of the cells studied may originate from an unwanted site (rectal cells in the vaginal smear.). No amount of skill and experience will enable the cytologist to render an accurate interpretation from a poorly obtained or fixed cellular sample [1-3]. He does a disservice to such patient if he accepts such smear for interpretation. Furthermore, a direct and close relationship and understanding should always exist between clinicians and cytologist if the full benefits of this method are to be obtained. Statistics have shown that a greater percentage of cancer related women mortality worldwide, especially Nigerians, comes from the cancer of the cervix [1-3]. This phenomenon has led to the introduction of cytological screening of women in clinic and other medical institution with a view of reducing the incidence of high mortality rate associated with cancer.

Therefore, the aim of this study was to identify these lesions early enough, make timely reports of same to the clinician and suggest methods of the patient's management.

\section{Materials AND Methods}

This chapter deals with the method used in carrying out the study of cervical cancer in the University of Nigeria Teaching Hospital, Enugu and environs.

\section{Sample Collection}

Collection of data consisted of collection of cervical smears from the clinics, fixation of smears and staining by both Papanicolaou's and Haematoxylin and Eosin methods and examined microscopically. Forty (40) samples of cervical smears was collected from each patients by the clinicians and sent to Histopathology Department of University of Nigeria Teaching Hospital, Enugu, after being immersed in 95\% ethanol.

For virtually all diagnostic cytology studies the best fixative is papanicolau's i.e. equal part of $95 \%$ ethanol and Ether. Because of its flammability, however, either detracts from the value of papanicolaou's fixative and most laboratories use $95 \%$ Ethanol alone. For laboratory use, the fixative may be placed in coupling jars, but general purpose, including office, hospital ward, or clinic practice, cytospray and spray-cyte are widely used as fixatives in office practice. In this work the researcher did not allow the smears to dry, as this would distort the morphology and alter the staining reactions of the cell. As soon as the smears were made, and while still moist, they were cytosprayed or fixed in the fixative and allowed to remain there for minimum of 15 minutes. However, prolonged periods in papanicolaou's fixative do not harm smears; indeed, it is preferable to take them directly from fixation to staining procedure rather than removing them and allowing them to dry in the interval [4].

We choose University of Nigeria Teaching Hospital, Enugu, because it is a big referral medical centre if excellence. It also attracts more patients from far and wide. It is believed that since University of Nigeria Teaching Hospital, Enugu remains the biggest hospital east of the Niger facilities for this study would be readily available. Again, we envisage that the patients attending gynaecology clinics would be able to offer themselves for smears collection and supply reasonable and acceptable clinical data that would facilitates meaningful cytodiagnosis.

Smears were submitted to the Department of Histopathology during the period of this study, from the family planning clinics, University of Nigeria Teaching Hospital, Enugu.

\section{Population Samples and Sample Technique}

Cervical smears were collected by competent clinicians from women of child-bearing age and above attending clinics in obstetrics and Gynaecology department. Double smears were collected from each women and a total of 1,240 women cytologically evaluated. Speculum and Ayre's spatula were used in specimen collection, and Papanicolaou's fixative (95\%) Ethanol was used, while in some cases smears were cytosprayed. 


\section{Staining methods} described.

The staining technique employed are the Haematoxylin and Eosin ( $\mathrm{H} \& \mathrm{E})$ and the Papanicolaou's method and both are

\section{RESULTS}

Nuclei

Superficial (cornfield) cells:

Intermediate (Non-confirmed cells)

Candida (Monilia)

Trichomonads

Parabasal Cells

$\begin{array}{ll}\text { - } & \text { Blue-Black } \\ \text { - } & \text { pink } \\ \text { - } & \text { green } \\ \text { - } & \text { red } \\ \text { - } & \text { grey-green } \\ \text { - } & \text { deep-green }\end{array}$

\section{RESULTS}

Table-1: Age Range, Year, Frequency Distribution, and Percentage Frequency of Cervical Cancer between 2009-2014

\begin{tabular}{|l|l|l|l|l|l|l|l|}
\hline AGE RANGE & 2009 & 2010 & 2011 & 2012 & 2013 & 2014 & TOTAL \\
\hline $25-29$ & - & - & - & - & - & - & $0(0 \%)$ \\
\hline $30-34$ & - & - & - & - & 4 & 2 & $6(15 \%)$ \\
\hline $35-39$ & 1 & 2 & - & - & - & - & $3(7.5 \%)$ \\
\hline $40-44$ & 1 & 2 & 3 & 2 & 3 & 1 & $12(30 \%)$ \\
\hline $45-49$ & 3 & - & - & - & 1 & 3 & $7(17.5 \%)$ \\
\hline $50-54$ & 2 & 1 & 2 & - & 1 & - & $6(15 \%)$ \\
\hline $55-59$ & - & - & - & 2 & 2 & - & $4(10 \%)$ \\
\hline $60-64$ & - & - & 1 & - & - & 1 & $2(5 \%)$ \\
\hline+++++++++++++++|| $\mid T O T A L$ & 7 & 5 & 6 & 4 & 11 & 7 & $40(10 \%)$ \\
\hline
\end{tabular}

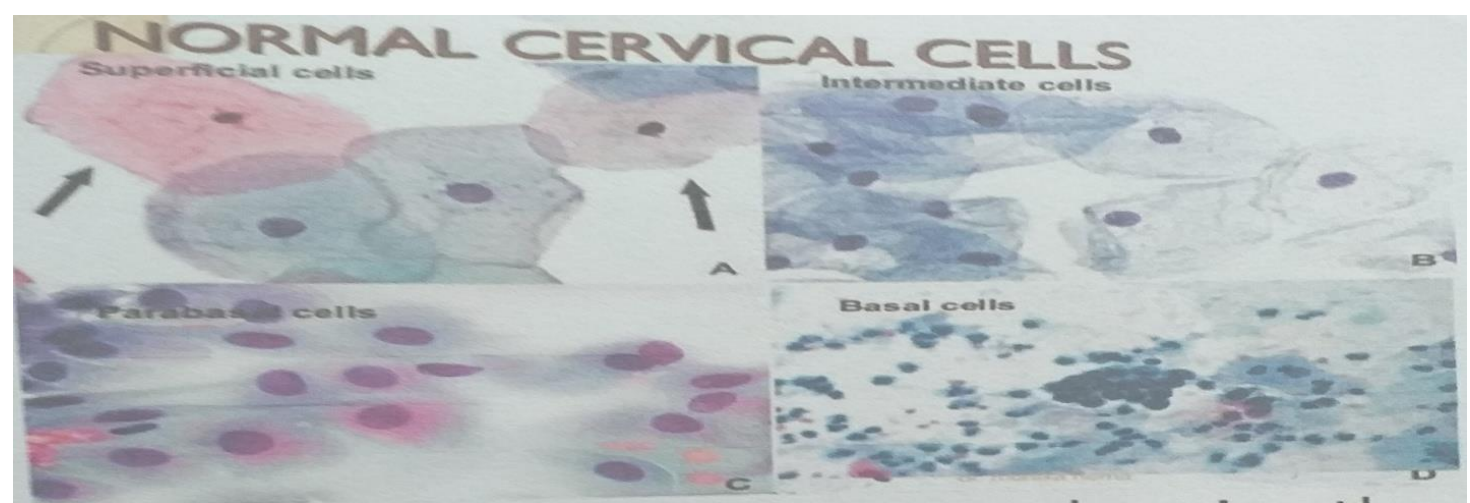

Fig-1: Normal cervical smear showing the superficial, squamous, parabasal cells. The nuclear cytoplasmic ratio (NR) is constant. Stain H and E

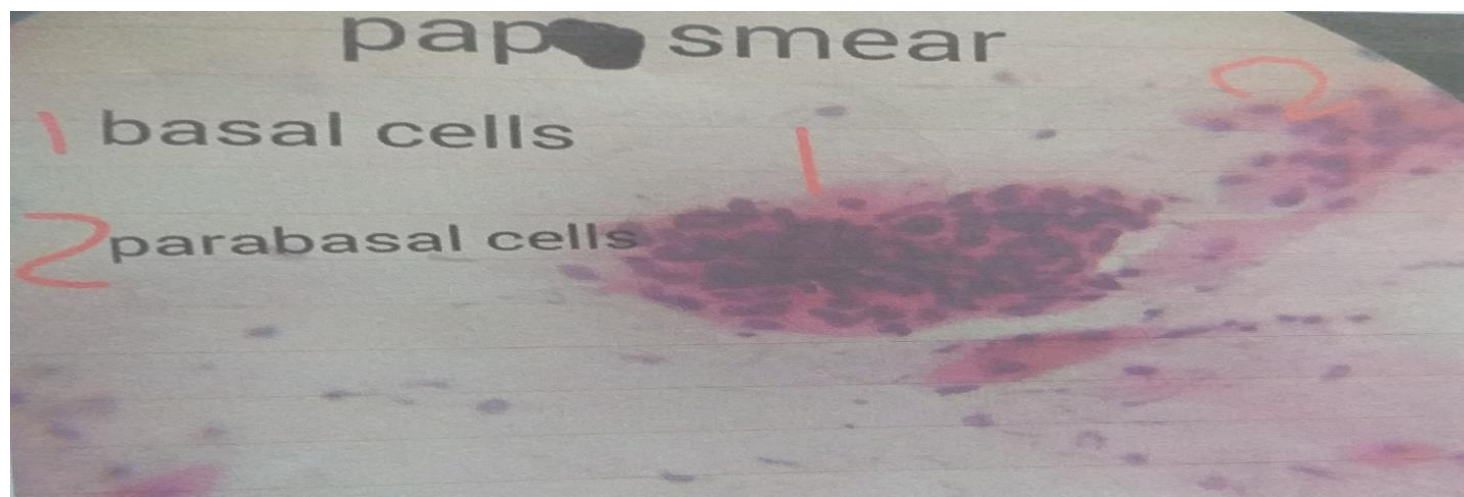

Fig-2: A mass of undifferentiated hyperplastic parabal cells $(P)$ demonstrated intense basophil. Stain $\mathrm{H}$ and $\mathrm{E}$ 


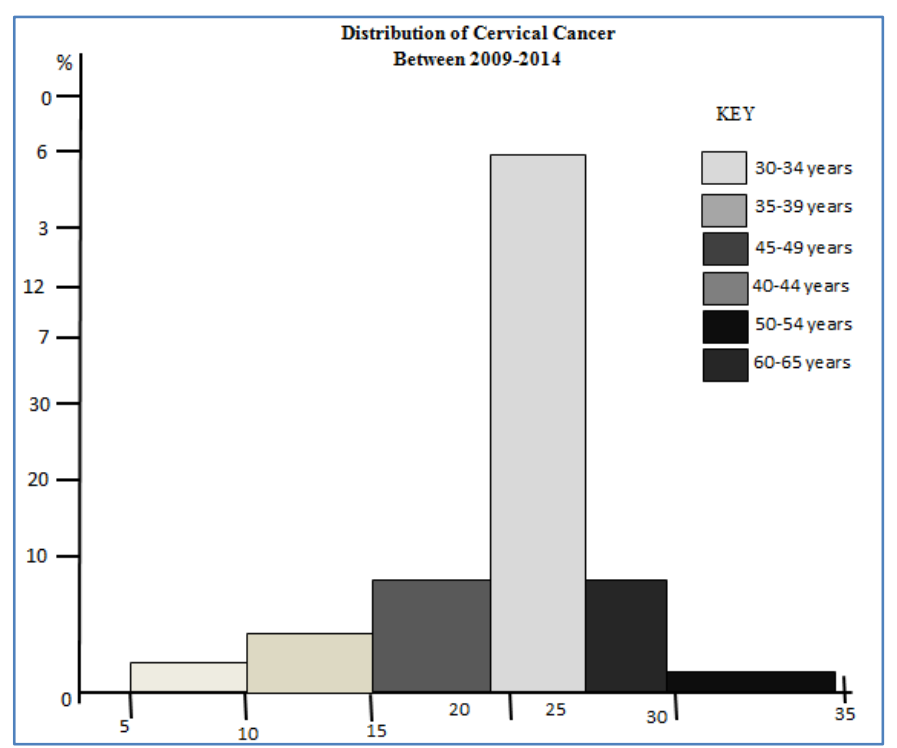

Fig-3: Histogram Representation of Age Range and Frequency

\section{Discussion}

This study shows that $72.60 \%$ of the subject used for cytological screening during the period under review had evidence of cervicitis. Ineffective cervictis represents $20.5 \%$ of the inflammable types. In view of the high incidence of this lesion, the researcher attributes this phenomenon to the life style of the group studied. This finding is in consonance with that of Anderson [1] whose clearly suggests a correlation with a particular life-style but it is virtually certain that one common link between these various of factors is early onset of sexual activity. In addition, the researcher noted that Candida albican, Trichomonas vaginalis, bacteria, Herpes simplex virus and warts virus infestation are responsible for the greater percentage of cervicitis encountered in this study $[5,6]$.

The researchers also found that $10.8 \%$ of the subject screened showed CIN of various grades. The researcher noted that most of the untreated cases of CIN1 progressed to CIN II and CIN to III, but in a few cases, CIN3 progressed on to obvious carcinoma of the cervix. The researcher was able to effectively monitor the cooperation of the clinicians during the 5 year study [8] Although the researcher did not investigate the specific etiology of these atypical, it is believed that sexual promiscuity, first coitus at less than 18 years of age, history of HPV, life time sexual partner and under nutrition are possible implicating factors. This assumption is made based on the fact that about $70 \%$ of women screened belong to the low socio economic group and it is in agreement with the findings of de-sanjose et al and Amburgey et al. [9, 10].

$10 \%$ of the population screened squamous cell metaplasia. This lesion is seen in women on high estrogen oral contraceptives. Evidence has shown that the acid PH of the vagina stimulates epithelium by a process of squamous metaplasia [11]. Squamous cell carcinoma of the cervix usually develops in the metaplastic epithelium of the transformation zone. This lesion must be adequate and effectively managed and treated, as the immature metaplastic cells are vulnerable to carcinogens which are transmitted at coitus and alter the cell genome to produce a cell line which has a neoplastic potential [11].

The researchers matched this incidence against parity and found that the incidence of cervical carcinoma increases with parity. Choo and Anderson [12] also pointed out in their various works that radiotherapy, smoking and immunosuppression respectively have been implicated in the secondary 'trigger' mechanisms. The finding also agrees strongly with the work of Munoz et al [13] who noted that high parity showed a significant effect on the partners of the husband. Epidemiological studies have demonstrated an association between squamous cell carcinoma of the cervix and early marriage, early pregnancy, a high number of pregnancies. Sexual promiscuity, divorce, sexually transmitted disease prostitution and low socio-economic status. It is believed that a carcinogen is transmitted sexually by the male at a time when the epithelium of the cervix is in an unstable state, i.e. when the transformation zone is undergoing squamous metaplasia during late adolescence. The researcher also found that the incidence of carcinoma of the cervix in the group studied has no relationship with a particular age group; rather its age distribution is random.

The study shows that $1.20 \%$ of the population under review showed normal cervical smears, while $3.6 \%$ of the smears appeared unsatisfactory and repeat smears indicated. We find Harris Haematoxylin and Eosin Technique good and adequate for this aspect of the study. 


\section{CONCLUSION}

The finding suggests that life-style, active sexual relationship and sexually transmitted diseases contribute significantly to cervicitis encountered in the study, while multi-parity, poor nutrition and sexual promiscuity are implicated in squamous cell carcinoma of the cervix and cervical intraepithelial neoplasia (CIN).

\section{RECOMMENDATIONS}

- We recommends that public education programme be mounted to educate the public on the need for cytologic screening of cervical smears. All women of child-bearing age and above should be screened at least once a year with a view for early detection of cervical carcinoma and other atypias. Government should provide funds and train enough manpower to cope with the anticipated increasing demand for the screening exercise.

- The federal government should, as a matter of policy, integrate cytological screening into the primary Health Care delivery. Government is advised to promulgate a decree making it an offence for couples to produce more than four children in their marriage career.

- We recommends Harris Haematoxylin and Eosin technique, in view of the current global economic austerity, as the technique has proved effective, good, adequate and affordable for this aspect of the study.

\section{REFERENCES}

1. Anderson. J.R. (2000). Intrauterine contrascoptic device, Muir Rextbook of Pathology, Edward. 2000;12 $12^{\text {th }}$ edition, 232

2. Gardner, B. I., Duke, C.D. (2005). Haemophilus Vaginallis Vaginitis: a newly defined specific infection previously classified nonspecific vaginitis. Am. J. of Obstet and Gynaecol. 69: 962-976.

3. Schiffman, M. A.(2000). Population-based study of human papillomavirus infection and cervical neoplasia in rural Costa Rica. J. Natl. Cancer Inst. (Bethesda), 92: 464-474,.

4. Papanicolaou, G.N., Traut. H.F. (1943). The diagnosis of uterine cancer, the vaginal smear, New York, 32-35.

5. Holmes, K. K., Stamm, W. E., \& Sobel, J. D. (1999). Lower genital tract infection syndromes in women. Sexually transmitted diseases. New York: McGraw-Hill, 761-81.

6. Heins B. R., Nathaniel.(1988). The role of smegna in cervical caricinome. Women Health. 1988:20-27.

7. Gupta, A. K., Nayar, M., \& Chandra, M. (1991). Reliability and limitations of fine needle aspiration cytology of lymphadenopathies. An analysis of 1,261 cases. Acta cytologica, 35(6), 777-783.

8. Rosenbaum, A. J., Gage, J. C., Alfaro, K. M., Ditzian, L. R., Maza, M., Scarinci, I. C., ... \& Cremer, M. L. (2014). Acceptability of self-collected versus provider-collected sampling for HPV DNA testing among women in rural El Salvador. International Journal of Gynecology \& Obstetrics, 126(2), 156-160.

9. Bosch, X. F., Muñoz, N., Chichareon, S., Ngelangel, C., Balagueró, L., Jacobs, M. V., ... \& Walboomers, J. M. (1999). Screening for genital human papillomavirus: results from an international validation study on human papillomavirus sampling techniques. Diagnostic molecular pathology: the American journal of surgical pathology, part B, 8(1), 26-31.

10. Amburgery, G.F., Van Eenwyk. J., David, F.C.(2004). Undernutrition as a risk factor for cervical intraepithelial neoplasia. J. of Nutri. Cancer. 20(1): 51-60

11. Snijders, P.J., Verhoef, V.M., Arbyn, M., Ogilvie, G., Minozzi, S., Banzi, R.(2013). Highrisk HPV testing on self-sampled versus clinician-collected specimens: a review on the clinical accuracy and impact on population attendance in cervical cancer screening. Int J Cancer, 132 (10):2223-36.

12. Choo, K. B., Pan, C. C., \& Han, S. H. (1987). Integration of human papillomavirus type 16 into cellular DNA of cervical carcinoma: preferential deletion of the E2 gene and invariable retention of the long control region and the E6/E7 open reading frames. Virology, 161(1), 259-261.

13. Munoz, N., Bosch, F. X., De Sanjose, S., Tafur, L., Izarzugaza, I., Gili, M., \& Gonzalez, L. C. (1992). The causal link between human papillomavirus and invasive cervical cancer: a population-based case-control study in Colombia and Spain. International journal of cancer, 52(5), 743-749. 